\title{
Poesia em Libras: expressão e compreensão a partir de vídeos na educação de surdos
}

\author{
Karin Lisiane Wentzel ${ }^{1}$, \\ Caroline Bohrer do Amaral ${ }^{2}$ \\ ${ }^{1}$ Universidade Federal do Rio Grande do Sul; karinwentzel@gmail.com; Brasil \\ ${ }^{2}$ Universidade Federal do Rio Grande do Sul; carol.bba@gmail.com; Brasil
}

\section{Resumo}

O presente trabalho tem por objetivo analisar o uso de uma filmagem em vídeo de duas poesias em Libras em uma escola pública bilíngue para surdos. Baseia-se em referenciais teóricos sobre educação de surdos, cultura visual e o uso das tecnologias como potencial de compartilhamento e registro da língua de sinais. Os dados apresentados compõem parte de uma pesquisa no formato de estudo de caso com abordagem qualitativa. $\mathrm{O}$ instrumento aplicado, é um vídeo com duas poesias em língua de sinais. A análise do vídeo é feita pelo grupo focal, formado por alunos surdos fluentes em Libras, através de um questionário com roteiro semiestruturado. Destaca-se ser primordial na educação de surdos o uso de tecnologias visuais como forma de registro documental, como forma de compartilhamento de conteúdos escolares e de publicações em repositórios digitais.

Palavras-chave: Surdos, vídeos, educação.

\section{Libras Poetry: expression and understanding from videos in deaf education}

\begin{abstract}
This paper aims to analyze the use of video footage of two poetry in Libras in a bilingual deaf public school. It is based on theoretical references on deaf education, visual culture and the use of technologies as a potential for sharing and registering sign language. The data presented are part of a case study research with a qualitative approach. The applied instrument is a video with two sign language poetry. The video analysis is made by the focus group, formed by deaf students fluent in Libras, through a questionnaire with semistructured script. It is noteworthy for being fundamental in the education of deaf people the use of visual technologies as a form of documentary record, as sharing of school contents and their publication in digital repositories.
\end{abstract}

Keywords: Deaf students, videos, education.

\section{Introdução}

Este trabalho compõe parte de uma pesquisa sobre ensino e aprendizagem por meio de vídeos em uma escola pública bilíngue para surdos. Este artigo tem o objetivo de apresentar dados relacionados à investigação sobre como a utilização de um vídeo em Libras, cujo enfoque é o gênero textual poesia, pode auxiliar no compartilhamento, na forma de registro documental de conteúdos trabalhados em sala de aula e no processo de aprendizagem escolar dos alunos surdos. 
Para análise do vídeo, foi realizado um grupo focal com quatro alunos surdos da escola. Durante o encontro do grupo focal, os alunos assistiram ao vídeo referido, seguindo-se de uma conversa orientada por um questionário semiestruturado para motivá-los a debaterem e a exporem seus pontos de vista sobre o material apresentado. Durante a conversa foram colocadas questões referentes à tecnologia, ao vídeo assistido e, de maneira mais ampla, à produção de filmagens e vídeos na língua de sinais e na forma de poesia.

Com os avanços tecnológicos, cada vez mais a mídia audiovisual está presente nas salas de aula dos alunos surdos, servindo para ilustrar ou para registrar as trajetórias das aprendizagens. Esses registros que até pouco tempo atrás ocorriam em cadernos, em folhas mimeografadas ou xerocadas, hoje estão nas telas, em cartões de memória ou na nuvem. É uma mudança significativa, servindo para ampliar o repertório linguístico dos estudantes e também melhorando a estética visual do que se dissemina em língua de sinais.

$\mathrm{O}$ acesso às tecnologias permitiu, no caso dos surdos, o registro visual, a ampla divulgação de diferentes assuntos em diferentes contextos e de diversas formas por meio da língua de sinais, de maneira direta entre o interlocutor e o receptor. Com esses recursos, o surdo ou usuário de Libras pode sinalizar e o espectador pode enxergá-lo e interpretá-lo, sem o intermédio de traduções ou de outras línguas. Constata-se atualmente um aumento de vídeos postados nas comunidades surdas, bem como se percebe que esse avanço tecnológico possibilita a interação, o registro e também o desenvolvimento das línguas de sinais, pois, conforme Finnegan (1977), estas tradicionalmente não apresentam um sistema escrito. Desta forma, o conhecimento cultural das comunidades surdas, que é passado por meio da língua de sinais, é transmitido visualmente, tornando-se evidente a necessidade de os surdos conhecerem bem a sua língua e dominarem os recursos tecnológicos aos quais têm acesso, de modo a ampliar os conhecimentos mencionados.

$\mathrm{O}$ artigo está organizado de modo que as seções seguintes correspondem a: referencial teórico, metodologia, discussão dos dados e resultados e considerações finais.

\section{A tecnologia como potencial da língua de sinais e da cultura visual na educação}

Este trabalho está embasado nos estudos de educação de surdos, levando em consideração a cultura visual e o uso das tecnologias para divulgar a língua de sinais. A Libras é uma língua visual, o comportamento de filmar ou fotografar configura-se como consolidação documental na língua natural. Desta forma, há necessidade de verificar como a filmagem de vídeo em Libras pode auxiliar no compartilhamento da língua para fins educacionais, na forma de registro documental de conteúdos trabalhados em sala e no processo de aprendizagem escolar dos alunos surdos.

A Libras é reconhecida como meio legal de comunicação e expressão das comunidades surdas do Brasil desde a publicação em 24 de abril de 2002 do decreto e sancionamento da Lei no. 10.436, que estabelece um verdadeiro marco histórico para todas as comunidades surdas do Brasil. Esse decreto, em seu parágrafo único, estabelece que a Língua Brasileira de Sinais - Libras - é uma forma de comunicação e expressão, com um sistema linguístico de natureza visual-motora, com estrutura gramatical própria, e que constitui um sistema linguístico de transmissão de ideias e fatos oriundos de comunidades de pessoas surdas do Brasil. 
O Decreto 5.626, de 22 de dezembro de 2005, no Art. $2^{\circ}$, considera a pessoa surda quando "[...] por ter perda auditiva, compreende e interage com o mundo por meio de experiências visuais, manifestando sua cultura principalmente pelo uso da Língua Brasileira de Sinais - Libras" (Brasil, 2005). Em seu parágrafo único, considera a "[...] deficiência auditiva a perda bilateral, parcial ou total, de quarenta e um decibéis $(\mathrm{dB})$ ou mais, aferida por audiograma nas frequências de $500 \mathrm{~Hz}, 1.000 \mathrm{~Hz}, 2.000 \mathrm{~Hz}$ e $3.000 \mathrm{~Hz}$ ". (Brasil, 2005).

Com o avanço das pesquisas, os estudos de Quadros (1997), Karnopp, (1994, 1997), Quadros e Pizzio, (2007) demonstraram que quanto mais cedo a criança surda estiver em contato com a língua de sinais, melhor será o seu desenvolvimento linguístico. Por intermédio do canal visual e espacial da língua de sinais, a criança vai adquirir a linguagem (Quadros, 2006). Com a aquisição de uma língua, que é percebida e significada ao longo do seu processo, a criança estará concebendo um mundo novo.

Para a maioria das pessoas surdas, a aquisição da língua de sinais ocorre tardiamente, pois o mais comum é haver apenas uma pessoa surda na família. Além desse fato, o diagnóstico da surdez nem sempre é feito nos primeiros anos de vida, então as crianças surdas "apresentam uma variação muito grande na quantidade de qualidade do input em Libras" (Quadros, 2013, p. 19), dependendo de quanto foram expostas à língua de sinais.

William Stoke, em 1960, publicou o seu estudo, no qual "percebeu e comprovou que a língua dos sinais atendia a todos os critérios linguísticos de uma língua genuína, no léxico, na sintaxe e na capacidade de gerar uma quantidade infinita de sentenças". (Quadros e Karnoop, 2004, p. 30). A partir desses estudos, foi possível comprovar que as línguas de sinais apresentam o que é fundamental para as línguas humanas, a dupla articulação. A presença de tal aspecto significa que existe um nível de significado constituído de morfemas, palavras, sintagmas e sentenças; e um outro nível, sem significado, que corresponde aos parâmetros fonológicos, que, no caso da língua de sinais, são configurações de mãos, locações e movimentos, os quais representam a mesma função dos sons nas línguas faladas.

No que se refere ao léxico, que é o acervo das palavras nas línguas orais, existe também um correspondente conjunto de sinais. Estes podem, algumas vezes, ser icônicos, que tentam imitar o referencial visual, mas, na maioria das vezes, não o são. Trata-se de um acervo em constante ampliação, pois novos sinais são criados, em virtude da necessidade de comunicação, e outros tornam-se obsoletos com o passar do tempo, assim como as palavras nas línguas orais. A Libras é composta de itens lexicais estruturados a partir de mecanismos morfológicos, sintáticos e semânticos, comprovando que a língua de sinais é a língua natural dos surdos.

Há diversos estudos que analisam a poesia em língua de sinais de diferentes países do mundo. No Brasil, Quadros (2006) faz essa análise de como a linguagem é usada para produzir efeitos poéticos nas poesias sinalizadas. Silveira e Karnopp (2013) analisaram a literatura surda de poesias em Libras, identificando recursos poéticos, as semelhanças e as diferenças entre poemas com a mesma temática.

Quadros (2006, p. 115) entende a poesia nas línguas de sinais, como um empoderamento dos povos surdos, pois são um grupo linguístico minoritários, na poesia "[...] celebra-se a língua de sinais, o estabelecimento dos olhares e a estética espacial" (Quadros, 2006, p. 10). Mesmo o prazer e o entretenimento proporcionados por essa arte podem ser vistos como um tipo de fortalecimento da cultura dos surdos. Ainda ressalta que o "empoderamento pode ocorrer pelo simples uso da língua, ou pela expressão de V. $17 \mathrm{~N}^{\circ}$ 3, dezembro, 2019 DOI: RENOTE 
determinadas ideias e significados que se fortalecem pela instrução, pela inspiração ou pela celebração" (Quadros, 2006, p. 115).

No cotidiano de uma escola bilíngue de surdos, percebe-se que a Libras não é apenas a língua de instrução, mas a língua pela qual os sujeitos estruturam os seus pensamentos, interagem com seus pares, representam sua cultura e inserem-se no mundo. A escolha deste trabalho pela análise do vídeo de uma expressão literária, a poesia, demonstra a importância da tecnologia para a divulgação, leitura, releitura, produção e reprodução da literatura surda inserida na cultura visual. Essa função significativa que a tecnologia proporciona a Libras e o uso desses recursos no ambiente escolar viabilizam que os alunos possam usufruir não apenas como espectadores, mas como leitores da Libras e como autores das suas poesias na sua língua natural.

As imagens visuais, disponibilizadas hoje pelo avanço tecnológico, permitem aos surdos um aumento nas suas interações com a própria língua, com a identidade e com a cultura surda. A imagem visual, da língua de sinais, necessita ser estudada e interpretada culturalmente, de acordo com Campello (2008), a percepção dos surdos está apoiada em imagens visuais, enfocando, assim, os aspectos da cultura, da língua e dos signos visuais. $\mathrm{O}$ termo "Cultura Visual", citado por Campello (2008, p. 125) vem sendo utilizado, desde 1972, por Michael Baxandall, tendo referências teóricas em Roland Barthes e Walter Benjamin. Posteriormente, George Roeder a definiu como uma forma de cultura que se vê". Essa abordagem da Cultura Visual, segundo Campello (2008, p. 125), “[...] reconhece a realidade de viver em um mundo de intermediação - culturalmente significativa da experiência visual, como no caso de sujeitos Surdos - e o conteúdo aparece em múltiplas formas, conteúdos e signos visuais e de 'transferir' de uma forma para outra". Esse autor cita Mirzoeff (1999), o qual define essa área como "uma tática para estudar as funções de um mundo abordadas através de fotos, imagens e visualizações, e não através de textos e palavras".

No ambiente escolar, os celulares dos próprios alunos ou dos professores possibilitam o registro de atividades desenvolvidas nas salas de aula: clicar e postar é tão adequado como ler e copiar. Amaral (2010, p.18) considera que a "ampliação da distribuição de tecnologia e variados produtos culturais provoca-nos a estudar a relação entre cultura, tecnologia e seus agentes (produtores, receptores e manipuladores)".

Com a tecnologia tão presente na vida de todos, os surdos também passaram a ter acesso a mais oportunidades de aprendizagem e de interação com um mundo para além da escola que frequentam. Nesse contexto, a Internet ganha grande relevância para a comunidade surda, em razão de: "[...] acesso, o potencial de interação, a quantidade de informações jornalísticas e a possibilidade de dispor de recursos visuais, como animações, imagens, vídeos e sinais gráficos" (Corrêa, 2017, p.4). Essas formas de compartilhamento, por exemplo, foram possíveis a partir do desenvolvimento da Web 2.0 que permitiu às pessoas, de uma maneira geral, produzir e publicar conteúdo digital em diferentes formatos; e especificamente, para os fins desta pesquisa, em vídeo, ampliando os desafios e as possibilidades da educação atual para além do uso do caderno e dos livros nas salas de aula. Essas práticas viabilizam-se por meio de softwares sociais e artefatos digitais, professores e estudantes, desta forma, "podem atuar de forma mais criativa com os conhecimentos, deixando um pouco de lado o livro didático e os textos prontos, para produzir textos a partir de outros ou, simplesmente, inovando" (Amaral, 2010, p. 57).

Com esse desenvolvimento tecnológico e de fácil acesso para as pessoas que possuem uma conexão de internet, surgem novas questões. Uma delas é a percepção atual 
de que o volume crescente de postagens em mídias como YouTube e Facebook nem sempre se traduz em cuidado com a qualidade do conteúdo. Considerando-se as afirmações de Lévy (1999, p. 146), de que "o mundo virtual funciona, então, como depósito de mensagens, contexto dinâmico acessível a todos e memória comunitária coletiva alimentada em tempo real", percebe-se a importância de registrar a língua de sinais de uma forma qualificada, de modo a preservar de forma eficaz a língua e a cultura de uma determinada comunidade surda.

A tecnologia, em especial a gravação em vídeo, proporcionou aos surdos a divulgação da Libras para pessoas surdas e ouvintes de todo o mundo. A partir deste avanço, as trocas em língua de sinais não dependem de emissores e receptores estarem fisicamente no mesmo lugar para haver comunicação na língua. De acordo com Lévy, a tecnologia possibilitou que as informações possam ser "compartilhadas entre numerosos indivíduos" e aumentando, portanto, "o potencial de inteligência coletiva dos grupos humanos." (Lévy, 1999, p. 53). Se antigamente era preciso que os surdos estivessem presentes para conversar, hoje em dia pode-se interagir com o outro tendo um celular e uma conexão com a internet.

O uso que os surdos fazem da tecnologia não tem por objetivo apenas a comunicação, mas também a visualização de sua língua, da sua identidade e cultura. Assim, para Schallenberger, "registrar a cultura surda é preservar a própria existência dos surdos" (2010, p. 69). Para este intento, conforme já mencionamos, tem se mostrado fundamental a utilização dos recursos tecnológicos disponíveis atualmente.

Por fim, pode-se afirmar quanto ao uso dessas tecnologias no ambiente escolar, conforme Amaral (2010, p. 68) aponta em seus estudos, “[...] que os artefatos tecnológicos digitais, permitem às práticas pedagógicas contemporâneas trabalhar a autoria, tanto dos alunos, como dos próprios professores". Cria-se, dessa forma, um ambiente favorável ao desenvolvimento cognitivo dos alunos surdos, visando, ao mesmo tempo, o compartilhamento linguístico.

\section{Metodologia}

Esta pesquisa tem caráter qualitativo, do tipo Estudo de Caso, pois, conforme Yin (2001, p. 19) "...é a estratégia escolhida ao se examinarem acontecimentos contemporâneos inseridos em algum contexto da vida real", ou seja, para fenômenos sociais.

Este trabalho compõe parte de uma pesquisa sobre ensino e aprendizagem por meio de vídeos em uma escola pública bilíngue para surdos no município de Porto Alegre. O objetivo geral deste trabalho é analisar como uma filmagem de vídeo em Libras, cujo enfoque é o gênero textual da poesia, pode auxiliar no compartilhamento, na forma de registro documental de conteúdos trabalhados em sala e no processo de aprendizagem escolar dos alunos surdos.

O público desta pesquisa é constituído de quarto adolescentes surdos, entre 14 e 16 anos. Por sigilo ético, a identidade dos participantes foi protegida, sendo referidos, neste trabalho, através de letras do alfabeto, E, F, G e H. Apesar de aprenderem Libras somente após ingressarem na escola, possuem um bom desenvolvimento linguístico, apresentando fluência em Libras e algum conhecimento em filmar e navegar na internet. A metade dos alunos participantes da pesquisa possui esses recursos tecnológicos e outra metade ainda não dispõe desses materiais.

Para coleta de dados, realizou-se um encontro entre a pesquisadora e os V. $17 \mathrm{~N}^{\mathrm{o}}$ 3, dezembro, 2019 DOI: RENOTE 
participantes no formato de grupo focal. O encontro foi filmado e, posteriormente, a conversa que ocorreu em língua de sinais foi transcrita para língua portuguesa. A pesquisadora inicialmente, apresentou a proposta da pesquisa, buscando conhecer, a partir da fala dos estudantes, como os professores usam vídeos nas suas aulas, se isso lhes ajuda a compreender melhor o conteúdo que está sendo trabalhado, se buscam outros vídeos na web por iniciativa própria para compreender conteúdos, entre outras questões. Em seguida, Os estudantes assistiram ao vídeo "A construção de um poema", que foi trabalhado em sala de aula utilizando a Libras e a língua portuguesa. Esse vídeo, que apresenta duas poesias em Libras, foi produzido por uma professora e um grupo de três alunos da instituição, encontra-se publicado ${ }^{1}$ na página da escola numa rede social. Na sequência, realizou-se uma conversa com o grupo focal a partir de um questionário semiestruturado, seguindo-se de perguntas que tinham como objetivo estimular o debate entre os alunos e a exposição de seus pontos de vista sobre o material apresentado. Questionou-se também sobre a poesia e aos elementos que remetem a esse gênero textual em Libras.

\section{Discussão dos dados e resultados}

Os dados apresentados neste artigo foram organizados em duas categorias, quais sejam: (1) vídeos e filmagens em Libras como forma de compartilhamento de conteúdos escolares e (2) Vídeos como registro de aprendizagem em Libras: a poesia.

\subsection{Vídeos e filmagens em Libras como forma de compartilhamento de conteúdos escolares}

Pensar na educação de surdos e na tecnologia é visualizar outras novas formas de compartilhamento de informações e de interações com o conhecimento. Durante o encontro do grupo focal, foi proposto que os alunos colocassem o que perceberam, compreenderam ou aprenderam assistindo ao vídeo e, as possibilidades que encontram utilizando os recursos de vídeos e de filmagens.

Os alunos $\mathrm{F}$ e $\mathrm{G}$ contribuíram para a conversa referindo-se aos vídeos que assistem no ambiente escolar e extraescolar. $\mathrm{O}$ aluno $\mathrm{F}$ contou que no ambiente escolar: "os professores na sala mostram vídeos, isso ajuda a compreender algumas coisas". Ele não especificou o que exatamente tem assistido em conjunto com os professores mas revela que é um recurso utilizado pelos docentes.

No ambiente extraescolar, o aluno G completou: "sim assisto, vejo alguns vídeos de português, de química, assuntos do dia do surdo, assuntos sobre viagem, diversas coisas eu fico assistindo". Este aluno percebeu os vídeos como subsídios para os conteúdos desenvolvidos pelos professores, como recursos que podem ser utilizados para a formação do estudante. $\mathrm{O}$ aluno $\mathrm{G}$ revelou também a autonomia para buscar meios de pesquisar a respeito dos assuntos de seu interesse e ampliar o seu conhecimento. Essas pesquisas provavelmente são feitas fora do horário de aula, não necessariamente ocorre com a presença dos pares, dos colegas ou professores ou dos usuários da língua de sinais. A internet possibilita o deslocamento tanto no tempo como no espaço, a comunicação a distância, a possibilidade de ver e rever inúmeras vezes conteúdos escolares, sem a necessidade da presença física do professor. Tais constatações sugerem, portanto, que assistir não é garantia de entender e aprender para alguns alunos, enquanto para outros o

\footnotetext{
${ }^{11}$ EMEF DE SURdos BILÍNGUE SALOMÃO WATNICK. “A Construção de um Poema” Post do
} 
recurso dos vídeos como fonte de pesquisa é natural, corriqueiro e de fixação do conhecimento.

O aluno E, quando foi perguntado se realiza pesquisas sobre os conteúdos assistidos em vídeos disponibilizados pelo professor, complementou: "uso o WhatsApp e, quando acho interessante, salvo o vídeo para depois mostrar para o professor S". Constata-se pelo relato que o aluno, a partir de seu interesse, apresenta um vídeo para o professor de determinado conteúdo para ser pensado, aprendido ou apenas compartilhado com a presença física de ambos, aluno e professor. Percebe-se que o professor apesar de todo avanço da tecnologia é a referência para o aluno. O educador tem um papel importante, servindo de mediador entre a tecnologia do que é veiculado e na formação do conhecimento do aluno. Conforme Buckingham (2010, p. 53) afirmou nos seus estudos, "a ideia de que a tecnologia em si mesma transformaria radicalmente a educação - e até mesmo resultaria no fim da escola - não passou de ilusão". Na escola de surdos, o professor se mantém como referência para seu público, pois é ele que compartilha a mesma língua, que muitas vezes a família não domina. O mesmo autor reconhece um outro papel que a escola está desempenhando, que é o de acesso aos equipamentos e às mídias, sendo "mais do que disponibilidade de equipamento, ou uma questão de habilidades técnicas: é também uma questão de capital cultural - a capacidade de usar formas culturais de expressão e comunicação". (Buckingham, 2010, p. 53).

\subsection{Vídeos como registro de aprendizagem em Libras: a poesia}

Nos últimos anos, podem-se encontrar mais postagens em Libras, com diferentes conteúdos, difundidas por meio dos sites do Facebook e YouTube. Também são inúmeros os estudos sendo realizados a partir de análises de vídeos de línguas de sinais. Essas formas de divulgação de pesquisas têm contribuído para um melhor desenvolvimento e aprimoramento da língua. A análise através de vídeos não era viável há alguns anos, então recorria-se às imagens fotográficas, transcrições ou pesquisas in loco para os trabalhos acadêmicos a respeito dos surdos e das línguas de sinais. $\mathrm{O}$ alcance da Libras no ambiente virtual tem demonstrado inúmeras oportunidades de interações e compartilhamentos entre os surdos ou usuários de língua de sinais.

Pesquisas sobre as poesias em línguas de sinais são bastante recentes, pode-se inclusive dizer que tiveram impulso com o uso da tecnologia, assim como, a crescente circulação desse gênero em diferentes ambientes virtuais, com um alcance mundial. Entende-se o conceito de poesia em língua de sinais, assim como de outras línguas, como uma forma intensificade de linguagem pois a linguagem na poesia está em primeiro plano, projeção esta que a difere do uso cotidiano. (Sutton-Spence e Quadros, 2006, p. 112).

Durante a conversa com o grupo focal, propôs-se, aos alunos, que explicassem a temática do vídeo assistido. Todos identificaram que se tratava de poesias. Essa constatação ocorre conforme o aluno D exemplificou: "é um jeito, é uma emoção, são as possibilidades da imaginação, das conexões que são feitas, de como ocorrem as inversões, as trocas. A forma como é feita a contação, o jeito, a possibilidade de 'abrir a mente' em sinais que é muito forte".

A poesia, como gênero literário permite associações harmoniosas de palavras e ritmos. Nas línguas de sinais, os sinais também são combinados, há um ritmo, uma entonação realizada pelos movimentos que os sinais são feitos e pela direção que tomam. Quem produz a poesia tem o objetivo de despertar a emoção de quem a assiste, revelando a criatividade por meio das escolhas de movimentos e ritmos. Está presente também o sentido 
do belo, o envolvimento estético e combinado dos sinais, necessários à elaboração da poesia e distintos de outras narrativas sinalizadas.

A poesia proporciona contar e contar-se de maneira diferente dos demais gêneros literários, o que também foi percebido pelo aluno G: "a pessoa olha de uma maneira diferente de quando ela está só sinalizando". O aluno percebeu o gênero em questão pela expressão corporal, que é tão importante na narrativa da língua de sinais quanto os fonemas das línguas orais. A expressão corporal da poesia é realizada de maneira diferente, como o aluno D observou: "se eu vou contar uma história, me viro, direita e esquerda, na poesia a pessoa fica muito parada". O aluno E contribuiu dizendo que a pessoa surda "...fica pensando: como posso fazer a poesia, como vou usar os sinais, como vou posicionar meu corpo". Essas questões de postura corporal, de como o corpo se coloca em determinado espaço enquanto sinaliza, é chamada de expressão corporal e é elemento gramatical da Libras.

No vídeo, aparece a aluna $\mathrm{K}$, depois a professora $\mathrm{J}$ e o aluno E, este é o mesmo que participa do grupo focal. Quando ele foi perguntado se entende tudo o que está sendo sinalizado, respondeu o seguinte: "então, com a poesia eu leio, acho um jeito de misturar sinais, palavras, liberar a minha expressão, contar, contar, cada vez mais perfeitamente, conseguindo fazer algo grande, expressivo, narrado, uma entrega". Esse desenvolvimento de apropriação dos sinais amplia as possibilidades de interação da língua com diferentes formas de uso que se pode fazer dela passando de leitor/receptor para um escritor/produtor sendo capaz de criar, escrever ou sinalizar. "A possibilidade criada pelas mídias digitais do aluno tornar-se também produtor torna urgente a necessidade de prepará-los para serem não apenas críticos e criativos, mas também produtivos" (Luz e Cruz, 2018, p. 2).

$\mathrm{O}$ ato de pensar a leitura ou escrita da poesia em Libras pode ser comparado inicialmente, conforme Perlin (1998, p. 54), escreve metaforicamente, ao ato de "abrir o baú que guarda os adornos que faltam ao personagem”. Inicialmente, é necessário ter um baú, ter contato prévio com a Libras, ter aprendido a língua, se apropriado dela em todos os seus níveis, para, então, abrir o baú dos recursos que permite aos seus usuários, usá-la nas suas diferentes formas e conteúdos.

\section{Considerações finais}

É pertinente pensar uma forma dos vídeos em língua de sinais serem disponibilizados pelas instituições de ensino visando a comunicação, mas principalmente o desenvolvimento cognitivo. No que se refere ao compartilhamento de conhecimento, as filmagens e vídeos em que os alunos aparecem, oportuniza a interação na própria língua. Pode-se fazer tal afirmação pois os alunos expressam-se na sua língua natural, fazem seus registros e têm a condições de fazerem leituras ou assistirem aos seus vídeos quantas vezes acharem necessário. Também são capazes de identificar seus equívocos e corrigi-los de forma eficiente. 
É pertinente pensar a escola de surdos como um novo espaço pedagógico, visualizando novas formas de registros da língua de sinais, da identidade e cultura surda. Trata-se de uma instituição capaz de produzir e compartilhar vídeos de modo a ampliar os conhecimentos dos alunos na sua língua natural e dentro de uma proposta bilíngue de educação. Faz-se importante publicar e buscar esses materiais através de repositórios digitais para que essas novas formas estejam disponíveis para a educação de modo mais acessível. Contando com o apoio e o desenvolvimento da tecnologia para elaboração de materiais didáticos produzido pelos alunos e para eles, bem como o apoio do professor, levando-se em consideração as peculiaridades do aluno surdo, que aprende através da língua de sinais, dentro de uma proposta de cultura visual.

Percebeu-se, a partir das falas dos alunos, que todos alunos reconheceram a poesia como gênero literário diferente dos demais, compreenderam a proposta do vídeo e a maioria ampliou o conhecimento da própria língua de sinais identificando um sinal que até então não conheciam. O vídeo, como registro de aprendizagem em Libras, serve para ilustrar como o desenvolvimento da língua de sinais é dependente dos recursos tecnológicos que se tem atualmente. No ambiente virtual, é somente através da gravação em vídeo que é possível fazer o registro e divulgação desse gênero literário na língua de sinais de forma fidedigna e autoral.

Apesar da tecnologia de filmagens estar acessível para uma boa parte de população, ela ainda não está presente no cotidiano de alguns jovens surdos, pois a metade dos alunos participantes da pesquisa possui esses recursos e outra metade ainda não dispõe desses materiais.

Por fim, como sugestão para continuidade deste trabalho, pesquisas futuras e contribuições para a educação de surdos, destaca-se que as mídias ampliam possibilidades, especialmente, em relação à compreensão do gênero poesia em Libras, sendo oportuno investigar outras tantas contribuições que os recursos tecnológicos podem oferecer ao processo de ensino e aprendizagem com esses estudantes. Assim, faz-se necessário dispor de condições de acesso a esses meios, democratizando e qualificando equipamentos e serviços tanto para o uso pessoal pelos surdos, quanto para o meio educacional. Este acesso dentro das escolas pode ser pensado na forma de registro de Libras, da identidade e da cultura das pessoas surdas. Além disso, vislumbra-se que o trabalho possa inspirar professores de diferentes disciplinas a utilizar, em conjunto com os alunos, ferramentas tecnológicas que podem potencializar o processo de ensino e aprendizagem. Sugere-se, também, que ampliar a pesquisa, com vídeos sobre outros conteúdos e novos grupos de alunos, sendo então possível comparar alunos que utilizam a tecnologia com outros que utilizam outra forma de aprendizagem para ver a mais eficiente.

\section{REFERÊNCIAS}

AMARAL, Caroline Bohrer do. Desafio da ciberinfância: modos de composição de práticas pedagógicas utilizando artefatos tecnológicos digitais. Mestrado em Educação, Universidade Federal do Rio Grande do Sul, Porto Alegre, 2010.

BRASIL. Decreto n. 5.626 - Regulamenta a Lei no 10.436, de 24 de abril de 2002, que dispõe sobre a Língua Brasileira de Sinais - Libras, e o art. 18 da Lei no 10.098, de 19 de dezembro de 2000, 22 de dezembro de 2005.

CAMPELlO, Ana Regina. Aspectos da Visualidade na Educação de Surdos. Tese de Doutorado. Florianópolis, 2008.

CORRÊA, Ygor; GOMES, Rafael P.; RIBEIRO, Vinícius G. A inclusão digital de surdos

V. $17 \mathrm{~N}^{\mathrm{o}}$ 3, dezembro, 2019

DOI:

RENOTE 
por meio de sites acessíveis em Libras: uma comunicação de mão única? In: RENOTE - Revista Novas Tecnologias na Educação, v. 15, p. 1- 10, 2017.

FINNEGAN, R. Oral poetry. Cambridge: Cambridge University Press. 1977.

LÉVY, Pierre. Cibercultura. São Paulo, Ed. 34, 1999.

LÜCKE, Menga; ANDRÉ, Marli E. D. A. Pesquisa em Educação: Abordagens Qualitativas. São Paulo: EPU, 1986.

LUZ, Sandra Dias. Cruz. Dulce Maria. Prática mídia-educativa na cultura digital: análise da produção de mapa mental como dispositivo móvel por estudantes do ensino fundamental. In: Novas tecnologias na Educação CINTED-UFRGS, V. 16 No 1, 2018.

PERLIN, G. Identidades Surdas. In: Skliar, Carlos (org.) A surdez: Um olhar sobre as diferenças. Editora Mediação. Porto Alegre, 1998.

QUADROS, R. M. de; KARNOPP, L. B. Língua de Sinais Brasileira: Estudos Linguísticos. Porto Alegre: Editora ArtMed. 2004.

QUADROS, Ronice. Estudos Surdos 1. Petropolis, RJ, 2006.

QUADROS, R. M. de, PIZZIO, A. L. Aquisição da língua de sinais brasileira: constituição e transcrição dos corpora In: Bilinguismo dos surdos. 1. ed. Goiânia: Cânone Editorial, 2007.

QUADROS, R. M. de, PIZZIO, A. L., REZENDE, P. L. F. Língua Brasileira de Sinais I. Universidade Federal de Santa Catarina Licenciatura em letras-Libras. Florianópolis 2009. Disponível

em:

http://www.libras.ufsc.br/colecaoLetrasLibras/eixoFormacaoEspecifica/linguaBrasileiraDe SinaisI/assets/459/Texto_base.pdf

SCHAllENBERGER, Augusto. Ciberhumor nas comunidades Surdas. Dissertação Mestrado em Educação, Universidade Federal do Rio Grande do Sul, Porto Alegre, 2010.

SUTTON-SPENCE, Rachel; QUADROS, Ronice. Poesia em língua de sinais: traços da identidade surda. In: QUADROS, Ronice (org.) Estudos Surdos I -série pesquisas. Rio de Janeiro: Arara Azul, 2006.

YIN, Robert K., Estudo de Caso: planejamento e métodos. 2. ed. Porto Alegre, Bookman, 2001.

EMEF DE SURDOS BILÍNGUE SALOMÃO WATNICK. "A Construção de um Poema" Post do Facebook. Disponível em: https://web.facebook.com/watnickoficial/videos/580224145508243/?hc_ref=ARReMnVw UM945py3jaq6SOuQLFQ3j1GRVG9kaElTCFDvSput14FJTveSvACtmqi2jE\&_xts_[0]= 68.ARBFR8TcsTINyPPJFnYK9m8RHSOxisjRVRyAKkB6Si2n8ae3csFB5ZdxsC8mND_r zj0KjDMcobHBptQ1QscQ5OScgjj85eB3JmAiIz5wzq54PEPrvslMCFjPOjmlvnJyYn7ycX A\&_tn__ =kC-R. Acesso em: 13 de Out. 2018. 